\title{
Crotalase, a Fibrinogen-Clotting Snake Venom Enzyme: Primary Structure and Evidence fora Fibrinogen Recognition Exosite Different from Thrombin
}

\author{
Agnes H. Henschen-Edman¹, Ida Theod or ${ }^{1,2}$, Brian F.P. Edwards ${ }^{3}$, Hubert Pirkle ${ }^{2}$ \\ From the Departments of Molecular Biology and Biochemistry ${ }^{1}$ and Pathology ${ }^{2}$, University of Ca lifomia, Irvine, CA, USA \\ and the ${ }^{3}$ Department of Biochemistry and Molecular Biology, Wayne Sta te University, Detroit, MI, USA
}

\section{Summary}

Crotalase, a fibrinogen-clotting enzyme isolated from the venom of Crotalus adamanteus, and its overlapping fragments were subjected to Edman degradation. The resulting amino acid sequence, VIGGDEC NINEHRFLVALYDYWSQLFLCGGTLINNEWVLTAAHCDRTHI LIYVGVHDRSVQFDKEQRRFPKEEKYFFDCSNNFTKWDKDIM LIRLNKPVSYSEHIAPLSLPSSPPIVGSVCRAMGWGQTTSPQET LPDVPHCANINLLDYEVCRTAHPQFRLPATSRTLCAGVLEG GIDTCNRDSGGPLICNGQFQGIVFWGPDPCAQPDKPGLYTK VFDHLDWIQSIIAGEKTVNCP, is characteristic of a serine proteinase. Comparison with thrombin, the physiological fibrinogen-clotting enzyme, showed that thrombin's fibrinogen-recognition exosite (FRE) is poorly represented in crotalase. Hirudin, a FRE-dependent inhibitor, had no effect on crotalase. Spatial modeling of crotalase yielded a possible alternative fibrinogen-recognition site comprised of Arg 60F, Lys 85, Lys 87, and Arg 107 (underlined in the sequence above). Crotalase also lacks thrombin's YPPW loop, as well as its functionally important ETW 146-148, and its heparin-binding site. The enzyme contains a single asparagine-linked glycosylation site, NFT, bearing neutral and amino sugars that account for $8.3 \%$ of the enzyme's total molecular weight of 29,027. The calculated absorbance of crotalase at $280 \mathrm{~nm}, 1 \%, \mathrm{~cm}^{-1}$ is 15.2 .

\section{Introduction}

Thrombin is a serine proteinase which catalyzes the last in the series of narrowly specific proteolytic reactions that lead to the clotting of the blood protein fibrinogen. Crotalase (EC 3.4.21.30) is an enzyme contained in the venom of the Eastern diamondback rattlesnake Crotalus adamanteus (1) which, like thrombin, triggers the clotting of fibrinogen by hydrolytic release of its fibrinopeptide A (FPA) (2). Venom enzymes with this thrombin-like action are widely distributed, mainly within several pit viper genera (3), and afford the opportunity for comparative examination of the molecular structural requirements for thrombin's narrow proteolytic action on fibrinogen.

In the present study, Edman degradation of the amino terminus and overlapping fragments of crotalase yielded a complete amino acid sequence with features characteristic of a serine proteinase. The fibrinogen recognition exosite (FRE) of thrombin is poorly represented in the crotalase sequence and this fact, along with the finding here that crota-

Correspondence to: Dr. Hubert Pirkle, Department of Pathology, Medical Sciences I, University of California, Irvine, California 92697 USA - FAX Number +1 949824 2160; Tel.: +1 949824 6575; E-mail: hcpirkle@ uci.edu lase is not inactivated by hirudin (a FRE-dependent inhibitor), prompted a search for an alternative fibrinogen recognition site. The resulting spatial modeling of the crotalase molecule in the present work and in Massova et al. (4) reveals a possible alternative FRE comprised of Arg 60F, Lys 85, Lys 87, and Arg 107 [chymotrypsinogen numbering (15)].

\section{Experimental Procedures}

\section{Materials}

Lyophilized venom of the Eastern diamondback rattlesnake (Crotalus adamanteus) was purchased from Biotoxins, Inc. (St. Cloud, FL). The following materials were obtained from the sources given in parentheses: trypsin-TPCK (Worthington Biochemical Corp., Freehold NJ), lysyl endopeptidase (Waco Pure Chemicals Industries, Tokyo), Sephadex G-50 and G-100 and SP Sephadex C-50 (Pharmacia), DEAE-cellulose, DE-52 (Whatman), Sepharose 4B aminocaproyl-p-aminobenzamidine, $o$-iodosobenzoic acid, and Staphylococcus aureus protease V8 (Pierce Chemical Co., Rockford, IL), radiolabeled iodoacetic acid (New England Nuclear Co., Boston), N-Glycanase (Genzyme Corp.), hirudin (Boehringer Mannheim), human $\alpha$-thrombin (gift from J.W. Fenton, II). Other reagents were the best available commercially.

\section{Purification of Enzyme}

Crotalase was purified from Crotalus adamanteus venom according to Bajwa and Markland (5). This procedure entails gel filtration on Sephadex G-100 followed by ion exchange chromatography on DEAE-cellulose, affinity chromatography on Sepharose 4B aminocaproyl-p-aminobenzamidine, and finally ion exchange chromatography on SP-Sephadex C-50. The product had a fibrinogen-clotting activity of 577 thrombin-equivalent $\mathrm{NIH}$ units/mg of protein using a previously described method (6).

\section{Carbohydrate Removal}

Crotalase ( $5 \mathrm{mg} / \mathrm{ml}$ in $0.2 \mathrm{M}$ phosphate buffer, 0.01 M EDTA, $\mathrm{pH}$ 8.6) was incubated with $\mathrm{N}$-Glycanase ( 2 units $/ \mathrm{mg}$ protein) at $37^{\circ} \mathrm{C}$ for $48 \mathrm{~h}$ and the deglycosylated protein was isolated by gel filtration on Sephadex G-50.

\section{Protein Modification}

Crotalase was denatured and reduced in $0.1 \mathrm{M}$ Tris, $\mathrm{pH} 8.5$ containing $6 \mathrm{M}$ guanidine hydrochloride and 5\% final concentration of 2-mercaptoethanol for $4 \mathrm{~h}$ under nitrogen at $37^{\circ} \mathrm{C}$ in the dark. Sulfhydryl groups were carboxymethylated with $\left[{ }^{3} \mathrm{H}\right]$ iodoacetic acid (7) or were pyridylethylated with 4vinylpyridine in a 1:1 molar ratio to all sulfhydryl groups. Free sulfhydryl groups were determined using 5,5'-dithiobis(2-nitrobenzoic acid) (8). Succinylation of free amino groups was carried out according to Habeeb et al. (9). 


\section{Chemical Cleavage}

Methionyl bonds of reduced and alkylated crotalase were cleaved in $70 \%$ formic acid containing $10 \%(\mathrm{w} / \mathrm{v})$ cyanogen bromide for $2 \mathrm{~h}$ at room temperature. Crotalase was cleaved at tryptophanyl bonds using $o$-iodosobenzoic acid (10), a 2 -fold (w/w) excess of which was added to the reduced and alkylated protein dissolved in $80 \%$ acetic acid, $4 \mathrm{M}$ guanidine hydrochloride.

\section{Enzymatic Cleavage}

Tryptic cleavage of reduced and alkylated crotalase was performed with or without prior succinylation in $0.1 \mathrm{M}$ ammonium bicarbonate $\mathrm{pH} 8.2$ with a 1:100 (w/w) enzyme to substrate ratio for $18 \mathrm{~h}$ at $37^{\circ} \mathrm{C}$. Cyanogen bromide fragments of crotalase were digested with Lys-C endoproteinase at a 1:40 (w/w) enzyme to substrate ratio for $8 \mathrm{~h}$ at $37^{\circ} \mathrm{C}$ in $0.1 \mathrm{M}$ Tris $\mathrm{pH}$ 8.6. Cyanogen bromide fragments were cleaved at Glu residues using Staphylococcus aureus $\mathrm{V} 8$ protease at a $1: 40(\mathrm{w} / \mathrm{w})$ enzyme to substrate ratio for $3 \mathrm{~h}$ at $37^{\circ} \mathrm{C}$ in $0.1 \mathrm{M}$ ammonium bicarbonate $\mathrm{pH} 8.0$.

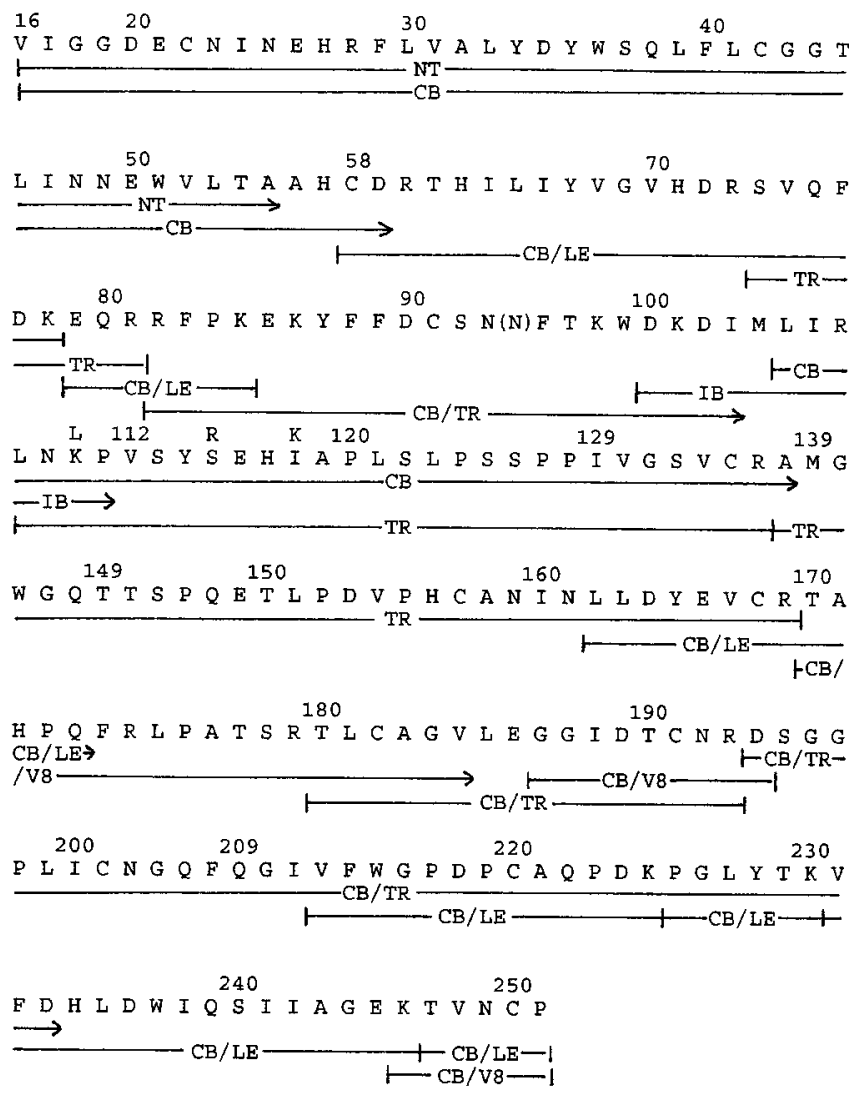

Fig. 1 Amino acid sequence of crotalase. Horizontal lines correspond to continuous sequences determined by automated Edman degradation. Short vertical lines indicate ends of sequenced peptides. Arrows indicate the end of satisfactory identification. Absence of any marking at either end of a horizontal line indicates continuity with the next or the preceding line of the diagram. NT, $\mathrm{NH}_{2}$-terminal sequence of intact S-alkylated molecule; $\mathrm{CB}$, cyanogen bromidecleaved peptide; TR, trypsin-digested peptide; IB, $o$-iodosobenzoic acidcleaved peptide; $\mathrm{CB} / \mathrm{LE}$, lysyl endoproteinase-digested fragment of a cyanogen bromide-cleaved peptide; $\mathrm{CB} / \mathrm{TR}$, trypsin-digested fragment of a cyanogen bromide-cleaved peptide; CB/V8, Staphylococcus aureus protease V8-digested fragment of a cyanogen bromide-cleaved peptide. $(\mathrm{N})$ is a glycosylation site. Polymorphic sites are shown as one residue symbol above another. Chymotrypsinogen numbering (15)

\section{Carbohydrate Analysis}

The neutral and amino sugars of crotalase were determined by Dr. Adriana Manzi, Glycobiology Core, University of California, San Diego using high performance anion exchange chromatography with pulsed amperometric detection (GlycoStation) after trifluoroacetic acid hydrolysis.

\section{Peptide Isolation}

Peptides generated by the chemical and enzymatic cleavage procedures were separated by open column chromatography on Sephadex G-50, eluted with a $0.2 \mathrm{M}$ ammonium bicarbonate buffer $\mathrm{pH} 8.0$, and on DE-52 using a linear $\mathrm{NaCl}$ gradient $(0$ to $0.2 \mathrm{M})$ in Tris buffer $\mathrm{pH} 7.8$ or by high performance liquid chromatography using a Beckman model 332 instrument with a Vydac C18 RP column. The gradient was linear from a starting eluant of $0.1 \%$ trifluoroacetic acid to a limiting eluant of $0.1 \%$ trifluoroacetic acid in $80 \%$ or $50 \%$ acetonitrile.

\section{Amino Acid Sequence Analysis}

Automated Edman degradation was performed with an Applied Biosystems Model 477A sequencer equipped with an on-line Model 120A phenylthiohydantoin amino acid analyzer or, earlier, with a Beckman 890B sequencer, in which case the PTH amino acids were identified by high performance liquid chromatography and by thin layer chromatography. The analyzer of the Applied Biosystems sequencer allowed direct identification of pyridylethylated PTH cysteine; radiolabeled, carboxymethylated PTH cysteine in the Beckman sequencer fractions was detected in a scintillation counter.

\section{Molecular Modeling}

The space-filling and secondary structure images of the crotalase molecule were generated by INSIGHT II (Kabsch-Sander algorithm for secondary structure; Molecular Simulations Inc.), using the coordinates of the model reported by Massova et al. (4).

\section{Hirudin Inhibition}

Crotalase (6.3 NIH thrombin-equivalent units $/ \mathrm{ml})$ was incubated with hirudin ( 30 antithrombin units $/ \mathrm{ml}$ ) in $0.15 \mathrm{M} \mathrm{NaCl} 0.02 \mathrm{M}$ Tris $\mathrm{pH} 7.4$ at $22^{\circ} \mathrm{C}$. Hirudin was in 1.4-fold molar excess over crotalase. The mixture was periodically tested for fibrinogen-clotting activity (6) for $30 \mathrm{~min}$. A comparable mixture of thrombin and hirudin showed immediate loss of fibrinogen-clotting activity.

\section{Results and Disc ussion}

\section{Amino Acid Sequence Determination}

The strategy for Edman degradation of crotalase and its overlapping fragments and the resulting amino acid sequence of the enzyme is given in Fig. 1. Here, the sequence analysis relied both on peptides generated by enzymatic digestion and on chemical cleavage of fragments produced by cyanogen bromide cleavage of the pyridylethylated or carboxymethylated protein.

\section{Primary Structural Features of Crotalase}

Comparison of the amino acid sequence of crotalase to those of chymotrypsin, kallikrein, trypsin, and thrombin [Fig. 2, chymotrypsinogen numbering (15)] reveals typical characteristics of a serine proteinase. The residues of the catalytic triad, His 57, Asp 102, and Ser 195, are in their expected positions, flanked by sequences that are 

CHY IVNGEEAVPGSWPWOVS LQDKT-GFHFGGGSLINENWWVTAAHCGVTTSD-_-_-_---VVVAGEE KAL VVGGYNCEMNSOPWOVAVYYF--GEYLCGGVIIDPSWVITAAHCAT DNYQVWLG-RNNLYEDEPEAOH TRY IVGGYTCGANTVPYOVS IN---SGYHFCGGSEINSQWVVSAAHCYKSGIQ---..---VR--LGED THB IVEGQDAEVGLSPWQVMLFRKSPQELLCGASLISDRWVLTAAHCLLYPPWDKNFTVDDLLVRI--GKH CrO VIGGDECNINEHRFLVAIYDYWSQL FLCEGTL NNNEWVLTAAHC------DRTH------ILTYVGVH AnC VIGGDECNINEHRFLVAVYEGTNWTF ICGGVWTHPEWVITREHC------ARRR------MNLVFGMH Mut VIGGDECNINEHRFLVAIYYDGLSGTF LGGGTIINQEWVITAROHC------NRSL------MNTYLGMH Bot VIGGDECDINEHPELAFMY--YSPQY FCGMTIINQEWVLTAAHC------DKTY------MRIYLGIH Bat VIGGDECDINEHPELAFMY--YSPRYFCGMTLINQEWVLTAAAHC------NRRT------MRIHLGKV Fla VIGGDECN INEHPELVALYDAWSGRFLCGGTLINPEWVLTAAHC------DSKNFK----MK--LGAH Bil IIGGDECN INEHRELVALY DVWSGSELCGGTLINQEWYLTAAHC------NMSN------IYIYLGMH CaI VIGGDECN INEHRFLVALYNSRSRTLFCGGTUINQEWVLTAAHC------ERNNE------RIKLGIH

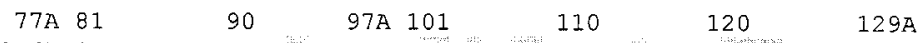

CHY DQGSSS-EKIQKLK-IAKVEKNSKYNSL-TINNDITLL-KUSTAASFSOTVSAVCUPSASD---DFAA KAL RLVSQSFPHPGFNQ-DLIWN-HTROPGDD-YSNDLMLLNHLSQPADITDGVKVIDIPIEEPK----VV TRY NINVVEGNEQFISASKSIV--HPS YN-SNTLNNDIMII I-KLKSAASLNSRVASISLPT SCAS-----A THB SRTRYERKVEKISMLDKIY-IHPRYNWKENLDRDIALL-KLKRPIELSDY IHPVCLPDKQTAAKLLHA CrO DRSVQFDKEQRRFPKEKYFFDCSNNFTKW--DKDIMEI-RENKPVSYSEHIAPLSLPSSPPI----V AnC RKSEKFDDEQERYPKKRYFIRCNKTRTSW--DEDIMLI-RINKPVNNSEHIAPLSIPSNPPI-----V Mut NKNVKEDDEQRRYPKKKKYFFRCNKNETKW--DEDI----RINRPVRFSAHTEPTSTPSNPPS-----E Bot TRSVANDDEVIRYPKEK--FICPNKKKNVITDKDIMLI-RINRPVKNST HIAPISIPSNPPS-----V Bat AGSVANYDEVVRYPKEK--FICPNKKKNVITDKDIMLI I-RIDRPVKNSEHIAPLSIPSNPPS-----V Fla SQKVLNEDEQIRNPKEK--FICPNKKNTEVLDKDIMUT-KIDSPVSYSEHIAPLSLPSSPPS-----V Bil NQSVQFDDEERRYPKEKYLFRCSKNFTKW--DKDIMLI-RINKRVRNSEHIAPLSLPSSPPI-----V CaI SKKVPNEDEQTRVPKEK--FFCLSSKNYTLWDKDIMLI-RLDSPVSNSEHIAPLSLPSSPPS-----V

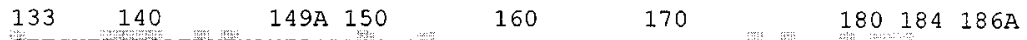
CHY GTTCVTTGWGLTRYTNANTPDRLQQASIHPLLSNTNCKK------YWGTKIKD--AMICAG----ASGV KAL GSTCLASGWGSITPDGLELS-----DDLECVN I DHLSNEKCVEAHKE-EVTD--LMLCAGEM--DGGK TRY GTQCLISGWGNTKSSG-TS----YPDVIKCLKAPILSDSSCKSAYPG-QITSN--MECAG YL--EDDK THB GFKGRVTGWGNRRETWTTSVAEVQPSVLQVVNLPLVERPVCKASTRI-RITDN--MFCAGYKPGEGKR CrO GSVCRAMGWGQ----DTSPQETLPDVPHCANINILDYEVCRTAHPQFRLPATSRTLCAGVL--EGGAnc GSDCRYMGWGS----INRR-IDVLSDEPRCANINLHN FTMCHGLFRKMPKKG--RVLCAGDL--RGRMut DSVCRVMGWGO----ITSP-PETLPDVPHCANINLFNYTVCRGAYP--RMP-T-KVLCAGVL---EGGBot GSVCRIMGWGA----ITTS-EDTYPDVPHCANIN LFNNTVCREAYNG--LPA--KTLCAGVL--QGGBat GSVCRIMGWGA----ITTS-EDTYPDVPHCANINI FNNTVCREAYNG--LFA--KTLCAGVL--QGGFla GSVCRIMGWGS----ITPV-EETFPDVPHCANINYLDDVECKPGYPEL-LPEY-RTLCAGVL--OGGBiI GSVCRVMGWGT----ITSP-NETLPDVPRCVNINI FNYTVCRGVFP--RLPERSRILCAGVL--EGGCaI GSVCRIMGWGR----ISPT-KETYPDVPHCANINLLEYEMCRAPYPEFGLPATSRTLCAGIL--EGG-

Hg. 2 Comparison of amino acid sequence thrombin-like venom enzymes with bovine thrombin and with other serine proteinases. Dashes indicate gaps introduced to optimize the alignment. All residue positions correspond to the first digit of the residue number. CHY, bovine chymotrypsin (35); KAL, rat pancreatic kallikrein (36); TRY, bovine trypsin (37); THB, bovine thrombin B-chain (38); Cro, crotalase (39); Anc, ancrod (40); Mut, Lachesis muta muta (41); Bot, bothrombin (42); Bat, batroxobin (12); Fla, flavoxobin (43), Bil, bilineobin (13), Cal, calobin (44). Chymotrypsinogen numbering (15)

$189 \quad 195 \quad 200 \quad 204 A \quad 210$

221A 226230

240

CHY -SSCMGDSGGPLVCKKN--GAWTLV-GIVSWGSSTCS-TSTPEVYARVTALVNWVOOTLAAN

KAL -DTCKGDSGGPLIC-----NGVLQ--GITSWGFNPCGEPKKPGIYTKLIKFTPWIKEVMKENP

TRY -DSCOGDSGGPVVC-----SGKLQ--GIVSWG-SGCAQKNKPGVYTKVCNYVSWIKQTIASN

THB GDACEGDSGGPFVMKSPYNNRWYOM-GIVSWG-EGCDRDGKYGFYTHVFRLKKWIOKVIDRLGS

CrO IDTCNRDSGGPLIC---NGQFQ--GIVFWGPDPCAQPDKPGLYTKVEDHLDWIOS IIAGEKTVNCP

Anc RDSCNSDSGGPIIC-----NEELH--GTVARGPNPGAQPNKPALYIS IYDYRDWVNNVIAGNAT--CSP Mut IDTGNRDSGGPLIC-----NGQFO--GIVFWGPDPCAQPDKPGVYTKVFDYLDWIOSVIAGNTT--CS

Bot IDTCGGDSGGPLIC-----NGQFQ--GILSWGSDPCAEPRKPAFYTKVEDYLPWIQSIIAGNKTATCPP Bat IDTCGGDSGGPLIC-----NGQEQ--GILSWGSDPCAEPRKPAFY TVWDYLPWICSIIAGNKTATCP

Fla IDTCGFDSGTPLIC-----NGQFQ--GIVYIGSHPCGQSRKPGIYTKVFDYNAWIOSIIAGNTAATCLP Bil IDTCKRDSGGPLIC-D-N-NGQFQ--GIVSWGPKRCAQPRKPALYSKU IDHLDWIOSI IAGNKTVNCP Cal KDTCRGDSGGPLIC-----NGQFQ- -GIASWEDDPCAQPHKPAAYTKVFDHLDWIQSIIAGNTDASCPP largely conserved. The only nonconserved neighboring residue is Arg 193, a position which turns out to be variable also in other thrombinlike enzymes (TLEs) (Fig. 2). As in all other serine proteinases position 194 of crotalase is occupied by an Asp residue which makes an important contribution to stabilizing the active center in a catalytically active configuration. In general this is accomplished by forming a salt bridge with the enzyme's N-terminal alpha amino group (11) and such a salt bridge is a feature of the modeled three-dimensional structure of crotalase (4).

Since crotalase has no free sulfhydryl groups (1) it is likely that all of its cysteines are disulfide bonded to one another. Based on homology with trypsin (12) and with another thrombin-like venom enzyme (13), the disulfide bridges of crotalase are predicted to link the following sequence positions: 22-157, 42-58, 91-250, 136-201, 168-182, and 191-220.

The overall rates of sequence identity between crotalase and the mammalian serine proteinases in Fig. 2 are kallikrein 33\%, trypsin $32 \%$, thrombin $30 \%$, and chymotrypsin $24 \%$. As might be expected, the
TLEs exhibit a much higher degree of similarity among themselves with a mean rate of identity of $64 \%$. The primary structures of crotalase and the other TLE are also strikingly similar to venom serine proteinases that do not clot fibrinogen (62\% mean rate of identity) (14).

Modeling of the spatial structure of the crotalase molecule shows its core to be comprised, like thrombin (15), of two six-stranded $\beta$-barrels between which lies the active center (Fig. 3). Other secondary structural features are three $\alpha$-helices formed from segments Tyr 165-Ala-171, Val 231-Leu 235, and Trp 237-Ala 243, homologous to three of thrombin's five B-chain helices.

A single consensus site for asparagine-linked glycosylation, Asn 94, was first inferred from a sequencing blank two steps before Thr 96 and later confirmed after enzymatic deglycosylation of the crotalase molecule. The total neutral and amino sugar content of crotalase is $8.34 \%$ with molar ratios of mannose 3 , galactose $6.1, \mathrm{~N}$-acetylglucosamine $10.5, \mathrm{~N}$-acetylgalactosamine 0.6 , and fucose 1.5 , a composition consistent with a complex type of asparagine-linked chain (16) and not with $O$-linkage. Analysis for sialic acid was not done since earlier 


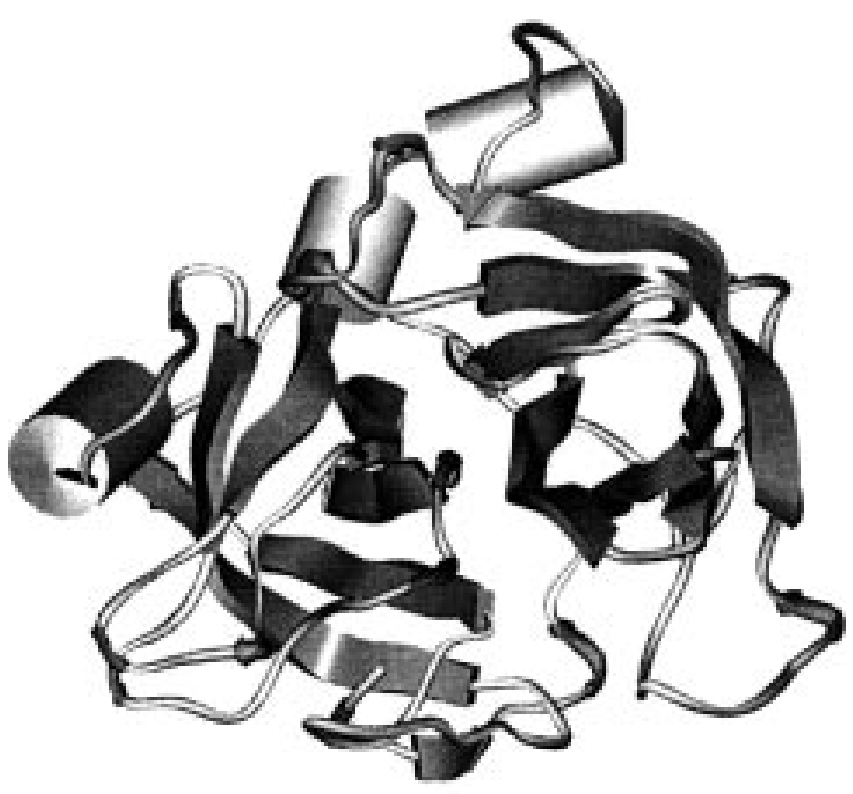

Fig. 3 Secondary structure diagram of the model of crotalase. The program INSIGHT II (Kabsch-Sander algorithm) was used to represent beta sheets as arrows (ribbons), helices as cylinders, and turns as sleeves

analyses yielded values that varied from one crotalase preparation to another $(1,5)$. Although $N$-acetylgalactosamine, as found here, does not ordinarily occur in asparagine-linked carbohydrate chains, it has now been demonstrated as subterminal to sialic acid residues of batroxobin $(17,18)$ and ancrod (19), partially or completely replacing galactose in that structural role. The unevenness of molar ratios among the individual sugars of crotalase most likely reflects the heterogeneity of carbohydrate chain structure often exhibited by glycoproteins.

From the amino acid sequence of crotalase its molecular weight can be computed as 26,606 without carbohydrate or 29,027 adjusted for the sugar content just given. From the enzyme's tryptophan, tyrosine, and cystine content its molar absorption coefficient, $\epsilon(280)\left(\mathrm{M}^{-1} \mathrm{~cm}^{-1}\right)$, can be calculated as 44,180 $(20,21)$. Then, assuming a molecular weight of 29,027 , the absorbance of crotalase at $280 \mathrm{~nm}, 1 \%, \mathrm{~cm}^{-1}$ is 15.2 .

\section{Comparison of Crotalase Sequence with Thrombin}

An important role in fibrinogen recognition and cleavage specificity has been attributed to the 60A-60D (YPPW) insertion loop of thrombin which forms part of the rim of its active site cleft (22). This feature is absent in crotalase, leaving a more open entrance to the active site (4). This feature is also absent in the mutant des-PPW thrombin (23). But both crotalase and the mutant thrombin exhibit, nonetheless, a narrow specificity for fibrinogen as a coagulant substrate. By contrast, a component of the opposite rim of the active site cleft of thrombin, ETW 146-148, also absent in crotalase, has been shown in mutant forms of thrombin to be critically important to its fibrinogen-clotting activity $(24,25)$. Thus, whatever the role of ETW 146-148 in the fibrinogenclotting activity of thrombin, the absence of this motif in clotting-active crotalase suggests a different mode of action for the venom enzyme.

Crotalase shares with thrombin and with other enzymes that cleave basic peptide bonds (e.g. kallikrein and trypsin, but not chymotrypsin, Fig. 2) a residue, Asp 189, located at the bottom of a "specificity pocket" near the active site $(4,26)$. This residue forms a salt bridge with the basic residue of the scissile bond, whose cleavage in the case of fibrinogen releases fibrinopeptide A (FPA) from the parent molecule.
Specificity for the release of FPA by thrombin is also served by a hydrophobic binding site near the catalytic center comprised of Tyr 60A, Trp 60D, Leu 99, Ile 174, and Trp 215 which interacts, in particular, with Phe 8 of the fibrinopeptide (26). As crotalase lacks any part of the 60 insertion loop, this hydrophobic site is formed instead by Trp 97A, Phe 174A, Leu 176, and Trp 215 and is favorably configured to accommodate Phe 8 of FPA (4). Other residues of crotalase that are homologous to thrombin's FPA-interacting amino acids are Lys 97 and Gly 216 (26).

Of the seven basic residues of thrombin that form its heparinbinding site (exosite 2) (15), only one is represented in crotalase, this in keeping with the insensitivity of crotalase to heparin (27).

\section{Fibrinogen Recognition Exosite (FRE)}

The remarkably narrow specificity of thrombin for fibrinogen and other macromolecular substrates is thought to reside largely in a surface groove that extends "southeast" from the active site cleft, using the conventional orientation of the molecule (28). The interaction of this fibrinogen recognition site (FRE) with a complementary site on the fibrinogen molecule has been, to a major extent, attributed to several positively charged residues at or immediately subjacent to this groove. Eleven basic residues of thrombin [R35, K36, R67, K70, R73, R75, R77A, K81, K109, R110 (human and bovine), K149E (human)] have been implicated in one way or another in this electrostatic interaction with fibrinogen $(29,30)$. However, of these 11 basic residues of the thrombin molecule, crotalase possesses only three and none of the three is conserved among the other TLEs (Fig. 2).

The absence in the TLEs of a cationic region homologous to the FRE of thrombin raises the question of whether the corresponding region of the crotalase might contain a similar, positively charged site made up of nonhomologous residues. But, in contrast to thrombin's net positive charge of 5 in the critical center of the FRE (positions 67-82), the same crotalase sequence has a positive charge of only 1 and most of the other TLEs have a negative net charge, usually of 1 (Fig. 2).

In addition to the foregoing structural grounds for doubting that crotalase recognizes fibrinogen through an interaction at the same region of the molecule used by thrombin, the following three function-

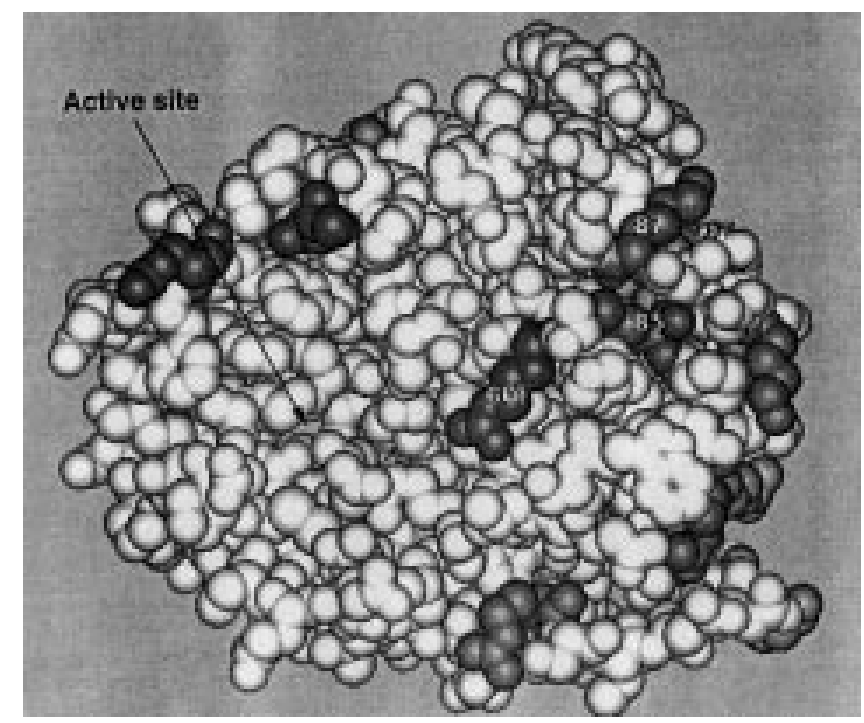

Fig. 4 Space-filling image of the model of crotalase generated using INSIGHT II. Basic amino acids are delineated as dark areas. Arrow points to active site cleft. Same orientation as Fig. 3 
al considerations point in the same direction. First, crotalase is not inactivated by the thrombin inhibitor hirudin. During $30 \mathrm{~min}$ of incubation (Experimental Procedures section, Hirudin Inhibition) hirudin-crotalase mixtures showed no change from control (hirudinfree) fibrinogen clotting times. In contrast, the thrombin-hirudin mixtures exhibited immediate loss of fibrinogen-clotting activity. Since it has now been shown directly that hirudin inhibits thrombin by binding to its FRE $(31,32)$, the failure of hirudin to affect the clotting activity of crotalase suggests a different fibrinogen recognition site. And hirudin-insensitivity is shared with other TLEs (3). A second functional consideration is that crotalase does not promote platelet aggregation (27). Triggering of platelet aggregation by thrombin entails cleavage of platelet thrombin receptor, mediated by binding of the receptor to the FRE of the enzyme (33). Thus, absence of a thrombinlike FRE in crotalase would constitute a sufficient explanation for the inability of crotalase to bring about platelet aggregation. Finally, Binnie and Lord (34) have shown that, while a fibrinogen peptide complementary to the FRE of thrombin competitively inhibits FPA release and clotting by thrombin, this peptide had no effect on these activities of crotalase's close homolog batroxobin.

The evidence for lack of a thrombin-like FRE in the crotalase molecule prompted a search for an alternative cationic fibrinogen recognition site. Fig. 4, generated using the coordinates of Massova et al. (4), shows the basic residues that present at the surface of the crotalase molecule. The right-hand lower part of the model shows the region that corresponds to the FRE of thrombin, as has already been discussed. The basic residues at the upper left can also be excluded as possible components of an alternative FRE as they are not conserved among the TLEs. The remaining residues, Arg 60F, Lys 85, Lys 87, and Arg 107 line a groove that extends from the active site cleft toward the northeast. Three of these residues are absolutely conserved among the TLEs and one is largely conserved. In the thrombin molecule, three of these positions are also occupied by basic residues but a crotalase-like groove is absent, as it is occupied by thrombin's 60A-60I loop (4). Thus, the cationic groove on the surface of the crotalase molecule, favorably oriented to its active site cleft, is a plausible candidate for an alternative fibrinogen recognition exosite.

It still must be considered, however, that fibrinogen recognition by crotalase may depend on totally different forces, e.g. hydrophobic interactions at yet a different exosite. Also, it is conceivable that interactions near the active site of crotalase may be sufficiently constrained to account for the observed degree of fibrinogen specificity.

\section{Acknowledgments}

This work was supported in part by NIH Grants HL-13598, HL-22875, HL-31267 (HP), HL-42412 (AH) and HL-57527 (BE). We thank Dr. Klara Osapay for generating images of the three-dimensional model of crotalase.

\section{References}

1. Markland FS, Damus PS. Purification and properties of a thrombin-like enzyme from the venom of Crotalus adamanteus (eastern diamondback rattlesnake). J Biol Chem 1971; 246: 6460-73.

2. Markland FS, Pirkle H. Thrombin-like enzyme from the venom of Crotalus adamanteus (eastern diamondback rattlesnake). Thromb Res 1977; 10: 487-94.

3. Pirkle H. Thrombin-like enzymes from snake venoms: An updated inventory. Thromb Haemost 1998; 79: 675-83.
4. Massova I, Pirkle H, Edwards BFP, Mobashery S. Insights into the threedimensional structure of crotalase: Implications for biological activity and substrate specificity. Bioorg Med Chem Lett 1997; 7: 3139-44.

5. Bajwa WW, Markland FS Jr. A new method for purification of the thrombin-like enzyme from the venom of the eastern diamondback rattlesnake. Thromb Res 1979; 16: 11-23.

6. Pirkle H, Theodor I, Miyada D, Simmons G. Thrombin-like enzyme from the venom of Bitis gabonica. Purification, properties, and coagulant actions. J Biol Chem 1986; 261: 8830-5.

7. Hirs CHW. Reduction and S-carboxymethylation of proteins. Methods Enzymol 1967; 11: 199-203.

8. Habeeb AFSA. Reaction of protein sulfhydryl groups with Ellman's reagent. Methods Enzymol 1972; 25: 457-64.

9. Habeeb AFSA, Cassidy HG, Singer SJ. Molecular structural effects produced in proteins by reaction with succinic anhydride. Biochim Biophys Acta 1958; 29: 587-93

10. Fontana A, Dalzoppo D, Grandi C, Zambonin M. Cleavage at tryptophan with $o$-iodosobenzoic acid. Methods Enzymol 1983; 91: 311-7.

11. Huber R, Bode W. Structural basis of the activation and action of trypsin. Acc Chem Res 1978; 11: 114-22.

12. Itoh N, Tanaka N, Mihashi S, Yamashina I. Molecular cloning and sequence analysis of cDNA for batroxobin, a thrombin-like snake venom enzyme. J Biol Chem 1978; 262: 3132-5.

13. Nikai T, Ohara A, Komori Y, Fox JW, Sugihara H. Primary structure of a coagulant enzyme, bilineobin, from Agkistrodon bilineatus venom. Arch Biochem Biophys 1995; 318: 89-96.

14. Pirkle H, Theodor I. Thrombin-like enzymes. In: Snake Venom Enzymes. Bailey GS (ed). Alaken, Inc., Fort Collins, Colorado 1998; 39-69.

15. Bode W, Turk D, Karshikov AJ. The refined 1.9- $\AA$ X-ray structure of D-Phe-Pro-Arg chloromethylketone-inhibited $\alpha$-thrombin: Structure analysis, overall structure, electrostatic properties, detailed active-site geometry, and structure-function relationships. Protein Sci 1992; 1: 426-71.

16. Kornfeld R, Kornfeld S. Assembly of asparagine-linked oligosaccharides. Ann Rev Biochem 1985; 54: 631-64.

17. Tanaka N, Nakada H, Itoh N, Mizuno Y, Takanishi M, Kawasaki T, Tate S-I, Inagaki F, Yamashina I. Novel structure of the N-acetylgalactosamine containing $\mathrm{N}$-glycosidic carbohydrate chain of batroxobin, a thrombin-like snake venom enzyme. J Biochem 1992; 112: 68-74.

18. Lochnit G, Geyer R. Carbohydrate structure analysis of batroxobin, a thrombin-like serine protease from Bothrops moojeni venom. Eur J Biochem 1995; 228: 805-16.

19. Pfeiffer G, Dabrowski U, Dabrowski J, Stirm S, Strube KH, Geyer R. Carbohydrate structure of a thrombin-like serine protease from Agkistrodon rhodostoma. Structure elucidation of oligosaccharides by methylation analysis, liquid secondary-ion mass spectrometry and proton magnetic resonance. Eur J Biochem 1992; 205: 961-78.

20. Pace CN, Vajdos F, Fee L, Grimsley G, Gray T. How to measure and predict the molar absorption coefficient of a protein. Protein Sci 1995; 4 : 2411-23.

21. Gill SC, von Hippel PH. Calculation of protein extinction coefficients from amino acid sequence data. Anal Biochem 1989; 182: 319-26.

22. Bode W, Mayr I, Baumann U, Huber R, Stone SR, Hofsteenge J. The refined $1,9-\AA$ crystal structure of human $\alpha$-thrombin: interaction with D-Phe-Pro-Arg chloromethylketone and significance of the Tyr-ProPro-Trp insertion segment. EMBO J 1989; 8: 3467-73.

23. Le Bonniec BF, Guinto ER, MacGillivray RTA, Stone SR, Esmon CT. The role of thrombin's Tyr-Pro-Pro-Trp motif in the interaction with fibrinogen, thrombomodulin, protein C, antithrombin III, and the Kunitz Inhibitors. J Biol Chem 1993; 268: 19055-61.

24. Le Bonniec BF, Guinto ER, Esmon CT. Interaction of thrombin des-ETW with antithrombin III, the Kunitz inhibitors, thrombomodulin and protein C. Structural link between the autolysis loop and the Tyr-Pro-Pro-Trp insertion of thrombin. J Biol Chem 1992; 267: 19341-8.

25. Dang QD, Sabetta M, Di Cera L. Selective loss of fibrinogen clotting in a loop-less thrombin. J Biol Chem 1997; 272: 19649-51. 
26. Martin PD, Robertson W, Turk D, Huber R, Bode W, Edwards BFP. The structure of residues 7-16 of the A $\alpha$-chain of human fibrinogen bound to bovine thrombin at 2.3- $\AA$ resolution. J Biol Chem 1992; 267: 7911-20.

27. Damus PS, Markland FS Jr, Davidson TM, Shanley JD. A purified procoagulant enzyme from the venom of the eastern diamondback rattlesnake (Crotalus adamanteus): In vivo and in vitro studies. J Lab Clin Med 1972; 79: 906-23.

28. Fenton JW II, Bing DH. Thrombin active-site regions. Sem Thromb Hemost 1986; 12: 200-8.

29. Stubbs MT, Bode W. A player of many parts: The spotlight falls on thrombin's structure. Thromb Res 1993; 69: 1-58.

30. Chang JY. Deciphering the structural elements of hirudin C-terminal peptide that bind to the fibrinogen recognition site of $\alpha$-thrombin. Biochemistry 1991; 30: 6656-61.

31. Rydel TJ, Tulinsky A., Bode W, Huber R. The structure of a complex of recombinant hirudin and human $\alpha$-thrombin. J Mol Biol 1991; 221: 583-601.

32. Vitali J, Martin PD, Malkowski MG, Robertson WD, Lazar JB, Winant RC, Johnson PH, Edwards BFP. The structure of a complex of bovine $\alpha$-thrombin and recombinant hirudin at 2.8-Å resulution. J Biol Chem 1992; 267: 17670-8.

33. Coughlin SR, Vu T-KH, Hung DT, Wheaton VI. Characterization of a functional thrombin receptor. Issues and opportunities. J Clin Invest 1992; 89: $351-5$.

34. Binnie CG, Lord ST. A synthetic analog of fibrinogen a27-50 is an inhibitor of thrombin. Thromb Haemost 1991; 65: 165-8.

35. Hartley BS, Kauffman D. Corrections to the amino acid sequence of bovine chymotrypsinogen A. Biochem J 1966; 101: 229-31.

36. Swift GH, Dagorn J-C, Ashley PL, Cummings SW, MacDonald RJ. Rat pancreatic kallikrein mRNA: Nucleotide sequence and amino acid sequence of the encoded preproenzyme. Proc Natl Acad Sci USA 1982; 79 : 7263-7.
37. Walsh KA, Neurath H. Trypsinogen and chymotrypsinogen as homologous proteins. Proc Natl Acad Sci USA 1964; 52: 884-9.

38. Magnusson S, Peterson TE, Sottrup-Jensen L, Claeys H. Complete primary structure of prothrombin: Isolation, structure and reactivity of ten carboxylated glutamic acid residues and regulation of prothrombin activation by thrombin. In: Proteases and Biological Control. Reich E, Rifkin DB, Shaw E (eds). Cold Spring Harbor Laboratory, Cold Spring Harbor, New York 1975; pp 123-49.

39. Pirkle H, Theodor I, Henschen A. Crotalase, a fibrinogen-clotting venom enzyme: Primary structure and evidence for lack of a fibrinogen recognition exosite homologous to that of thrombin. Haemostas 1996; 26 (Suppl 3): 452 (Abstract).

40. Burkhart W, Smith GFH, Su J-L, Parikh I, LeVine H III. Amino acid sequence determination of Ancrod, the thrombin-like $\alpha$-fibrinogenase from the venom of Akistrodon rhodostoma. FEBS Lett 1992; 297: 297-301.

41. Magalhães A, Da Fonseca BCB, Diniz DR, Gilroy J, Richardson M. The complete amino acid sequence of a thrombin-like enzyme/gyroxin analogue from venom of the bushmaster snake (Lachesis muta muta). FEBS Lett 1993; 329: 116-20.

42. Nishida S, Fujimura Y, Miura S, Ozaki Y, Usami Y, Suzuki M, Titani K, Yoshida E, Sugimoto M, Yoshioka A, Fukui H. Purification and characterization of bothrombin, a fibrinogen-clotting serine protease from the venom of Bothrops jararaca. Biochemistry 1994; 33: 1843-9.

43. Shieh T-C, Kawabata S-I, Kihara H, Ohno M, Iwanaga S. Amino acid sequence of a coagulant enzyme, flavoxobin, from Trimeresurus flavoviridis venom. J Biochem 1988; 103: 596-605.

44. Hahn B-S, Yang K-Y, Park E-M, Chang I-M, Kim Y-S. Purification and molecular cloning of calobin, a thrombin-like enzyme from Agkistrodon caliginosus (Korean viper). J Biochem 1996; 119: 835-43.

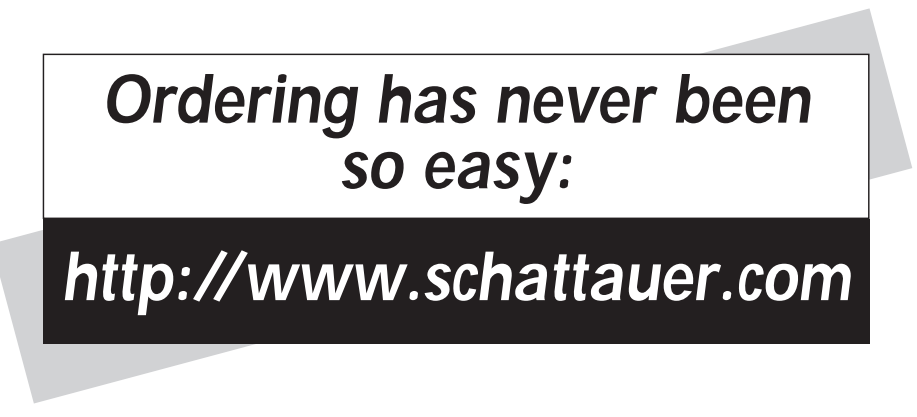

